\title{
Subjunctive, habituality and negative polarity items
}

\author{
Anastasia Giannakidou \\ University of Groningen
}

\section{Preliminary}

Since the seminal work of Fauconnier (1975) and Ladusaw (1980), it is standardly assumed that negative polarity items (NPIs) occur only in scale reversing contexts, sentence negation being one such context. Ladusaw (1980) identifies downward entailment (or, monotone decreasingness (MD)) as the semantic property giving rise to scale reversal. $\mathrm{MD}$ functions are order reversing functions as shown in definition (1):

(D1) A function is monotone decreasing iff for each arbitrary element $\mathrm{X}, \mathrm{Y}$ it holds that: $\mathrm{X} \subseteq \mathrm{Y} \Rightarrow f(\mathrm{Y}) \subseteq f(\mathrm{X})$

Expressions which denote MD functions allow inference from sets to subsets in their scope. In MD contexts, expressions denoting sets can be substituted for expressions denoting subsets salva veritate. (1) and (2) below show that the NP no children validates the MD pattern whereas the NP some children does not:

$$
\begin{array}{ll}
\text { No children like ice cream } & \rightarrow \\
\text { No children like Italian ice cream } & \\
\text { Some children like ice cream } & -/ \rightarrow \\
\text { Some children like Italian ice cream } &
\end{array}
$$

The requirement that NPIs be in the scope of expressions denoting MD functions is posed as a necessary and sufficient condition for NPI-licensing in a Ladusaw-type theory. This way, the well-formedness of anything in (3) and its ill-formedness in (4) are correctly predicted:

No children saw anything.

$$
\text { * Some children saw anything. }
$$

Yet, it tums out that there is a significant number of constructions (inter alia, questions and superlatives in English) which, without exemplifying any monotonic properties, do allow NPIs to appear. Crosslinguistic investigation comes to support this observation. Certain Greek polarity indefinites, reproduced under (5), exemplify a much broader distribution than their English and Germanic counterparts:

$\begin{array}{ll}\text { kanénas } & \text { 'anyone' } \\ \text { típota } & \text { 'anything' } \\ \text { poté } & \text { 'ever' }\end{array}$


puthená 'anywhere'
kathólu 'at all'

As expected, these indefinites are licensed in the classic affective contexts (sentence negation, yes/no and rhetorical wh-questions, the first argument of universal quantifiers and the scope of MD NPs in general, the clausal argument of $\mathrm{MD}$ predicates, conditionals (factual/counterfactuals), the comparative, the superlative, prin 'before' and xoris 'without' clauses). Additionally, Greek NPindefinites are grammatical in contexts in which NPIs, as known from languages like English or Dutch, can not appear. The list of the additional polarity sensitive contexts includes subjunctive main and complement clauses (ex. (6)-(9)), imperatives (ex.(10)), the scope of modal verbs (ex.(11)) and habitual sentences (ex.(12)):

(6) na akús kamjá simvulí, tha su vií se kaló

SUB listen-2sg any advise, FUT you-GEN come-out in good

Listen to some advice, it will prove to your advantage

(7) thélo na pjó kamja birítsa

want-1sg SUB drink-1sg any beer

I want to drink a beer.

(8) i etería zitá énan ipálilo pu na kséri típota sxetika me lojistikí

the company asks-for an employee who-SUB know-3sg anything

about accounting

The company is looking for an employee who knows something

about accounting.

(9) kánis sa na íse kanéna korítsi 18 xronón

do-pres-2sg as-if be-pres-2sg any girl 18 years

You behave as if you are some 18-year-old girl

(10) rótise kanénan idikó

ask-you-IMP any specialist

Ask a specialist.

(11) prépi na ton dhi kanénas jatrós

must-3sg SUB him see any doctor

A doctor must see him.

(12) mas stélni pu ke pu kanéna gráma

us send-3sg where and where any letter

He sends us a letter every now and then.

A similar pattern is attested in Rumanian. Polarity items are licensed in subjunctive (ex.(13)) and habitual (ex.(14)) sentences as well:

(13) Sper sa fi ramas vreo bucata de prajitura hope-1sg-PRES SUB be left any piece of cake 'I hope there is a piece of cake left.' 
(14) $\mathrm{Nu}$ faceam nimic. Ori visam ori ma intilneam cu vreo fata si alavrageam toata ziua not do-past-1sg nothing. either dream-past-1sg or me meet-past -1 sg with any girl and chat-past-1sg all day

I wasn't doing anything. I was either dreaming or meeting girls and chatting the whole day.

The behavior of Greek and Romanian NPIs suggests that monotonicity-based licensing theories face serious empirical problems. The fact that at least some NPIs are licensed in constructions with no inherent monotonic properties shows that downward entailment does not suffice to characterize the class of NPIlicensers as a natural class ${ }^{1}$. The present paper focuses on the licensing in subjunctive and habitual sentences. I opt to demonstrate that a felicitous account can be given once we appeal to a theory which attributes the licensing potential to the non-veridical character of the licensing contexts (Giannakidou 1994). This theory should be properly regarded as a generalization of Ladusaw's theory in a sense to be made precise. The discussion is based on data drawn primarily from Greek.

\section{Mood choice and polarity items}

The link between mood and negative polarity as exemplified in Greek is considered in Giannakidou (1994). In this section, I review the basic aspects of the hypothesis advocated in that study in order to argue that the subjunctive itself is to be treated as a polarity item.

\section{1. The non-veridical licensing of NPIs}

The analysis in Giannakidou (1994) can be summarized as follows:

(i) The Greek polarity indefinites are licensed in subjunctive main and complement clauses. Crucially, these items are excluded from indicative clauses, cf. (15)-(16):

elpízo na féris kanénan filo su sto párti hope-1sg SUB-bring-2sg any friend yours in-the party

I hope you'll bring a friend of yours to the party.

oniréftika *oti irthe kanénas

dream-past-1sg that-IND come-past anyone

(I dreamt that someone came)

This contrast can be explained if we assume that the crucial notion which characterizes licensing environments is non-veridicality. As shown in (17), an operator $O p$ is non-veridical iff $O p$ does not imply $p$; $O p$ is veridical iff $O p$ implies $\mathrm{p}$ (where $\mathrm{p}$ is an arbitrary proposition): 


$$
\begin{array}{ll}
\text { Op }-1 \rightarrow p & \text { non-veridicality } \\
\mathrm{Op} \rightarrow \mathrm{p} & \text { veridicality }
\end{array}
$$

The discussion in Giannakidou (1994) is confined to one-place propositional operators but, in principal, it can be extended to non-propositional operators as well. The intuitive idea behind (17) is that $p$ denotes a fact (an actualized event) when embedded in a veridical domain and a non-fact (a non-actualized event) when embedded in a non-veridical domain.

(ii) In Greek, predicates and operators which create non-veridical contexts select the subjunctive whereas predicates and operators giving rise to veridical contexts select the indicative. The characterization of predicates like believe, imagine and dream as veridical is justified by means of a relativized version of extensionality/veridicality along the lines of Farkas (1992). Farkas makes use of a modal semantics which consists of a set of models $M$, each model in the set having its own 'actual world'. That is, besides the special world taken to model reality $\left(\mathrm{W}_{\mathrm{R}}\right)$ she singles out worlds that represent reality according to particular individuals, the individual anchors in her terminology. The indicative signals that a proposition is extensionally anchored, i.e. it is anchored to the real world of some model (Farkas 1992b, (14)), not necessarily to $\mathrm{W}_{\mathrm{R}}$. The subjunctive designates that a proposition is intensionally anchored, i.e. it is anchored to the set of words introduced by the matrix predicate and not to a particular actual world thereof. To illustrate how epistemic, fiction and assertive predicates are to be understood as veridical, consider (16) above and (18)-(19) below:

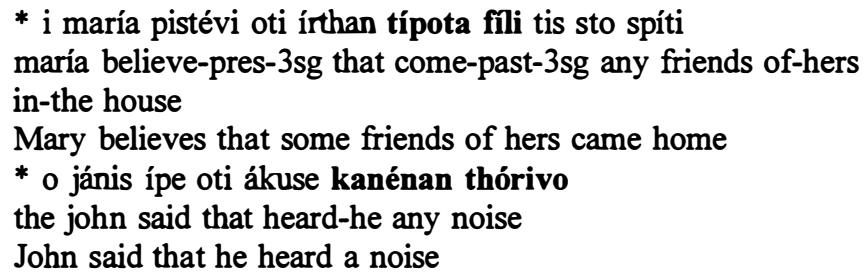

Epistemic predicates, like believe in (18), introduce the actual world according to the referent of their subject. Due to the lexical meaning of the verb pistévo 'to believe', for (18) to be true, the complement proposition must belong to the propositions that Maria takes to be true of the actual world. Accordingly, the complement of assertive predicates like léo 'to say' in (19) is anchored to the real world of the model of reported conversation. For (19) to be true it is required that the complement proposition is placed among the propositions that John takes to be true in the context of the reported conversation. Finally, in (16), the fiction verb onirévome 'to dream', introduces a fictional reality which is substituted for the real world. For (16) to be true, the complement proposition must belong to the set of propositions that the speaker takes to be true of the fictional world. Indicative clauses are all being anchored to the real world of some model. The difference resides in what the model is: the model 
of some individual's worldview (epistemics), the model of a dream or of a fiction (fiction predicates), the model of reported conversation (assertives) or the model of current conversation (factives). The (relativized) veridicality of the predicates under consideration is represented in (20):

(20) $\mathrm{W}_{\mathrm{r}}(\mathrm{m}) \mathrm{B}(\mathrm{m}) \mathrm{p} \rightarrow \mathrm{p}$ $W_{r c}(j) R(j) p \rightarrow p$

$\mathrm{W}_{\mathrm{d}}(\mathrm{s}) \mathrm{D}(\mathrm{s}) \mathrm{p} \rightarrow \mathrm{p}$
[ $\mathrm{W}_{\mathrm{r}}(\mathrm{m})$ :real world relevant to Maria, B:believe] $\left[\mathrm{W}_{\mathrm{rc}}(\mathrm{j})\right.$ : reported conversation world relevant to John, R:report] $\left[\mathrm{W}_{\mathrm{d}}(\mathrm{s})\right.$ : dream world relevant to the speaker, D:dream]

In this frame, extensionality is not synonymous to factivity but rather, the latter is subsumed under the former as a particular instance thereof. Predicates can be extensional without being factive. Factive predicates like be glad and know simply form a special case of extensional predicates in that they express attitudes which belong to the real world, unless, of course, they are embedded in a non-extensional domain as in John dreamt that he was glad that Mary arrived.

(iii) NPIs are ungrammatical in indicative clauses because indicative clauses are veridical. On the contrary, NPIs are grammatical in subjunctive clauses because these clauses are non-veridical due to the fact that they are selected by predicates which function as non-veridical operators. We will come back to this in the next section. On the basis of (i)-(iii), the following licensing condition is proposed:

\section{Licensing Condition for NPIs}

NPIs are functors which require their arguments to be modal in the sense of non-veridical. For them to be licensed it is required that they occur within the scope of non-veridical operators. ${ }^{2}$

The crucial premise is that all licensing environments can be characterized as non-veridical. In view of the fact that no propositional operator can be both veridical and monotone decreasing with respect to a single argument place, it follows that all $\mathrm{MD}$ operators are non-veridical. The non-veridicality test illustrates the validity of this claim ${ }^{3}$ :

negation:

MD predicate:

John is not a student $-/ \rightarrow$ John is a student

MD NP: John refused to see me $-/ \rightarrow$ John saw me

without: No one saw John $-/ \rightarrow$ John was seen

before: conditional: without consulting me $-/ \rightarrow \mathrm{x}$ consulted me before he saw anyone $\quad-/ \rightarrow$ he saw $x$ If he comes $-/ \rightarrow$ he comes

$\mathrm{MD}$ operators constitute a subset of non-veridical operators. It is in this sense that (21) can be regarded as a generalization of a monotonicity-based licensing condition. The empirical merit of $(21)$ is that it predicts the NPI-licensing facts 
in Greek as well as in more "strict" languages like English and Dutch by bringing a notion wider than monotonicity into play. By postulating (21) a broad range of data are covered, otherwise unexplained in monotonicity-based licensing theories, without losing the advantages monotonicity affords.

\section{2. The Greek subjunctive as a polarity item}

As we have seen, the main claim in Giannakidou (1994) is that non-veridicality is implicated in both mood selection and the licensing of NPIs. This assumption squares neatly with the crosslinguistic observation that the subjunctive is selected by, among others, $\mathrm{MD}$ expressions. In this section I would like to push the claim in Giannakidou (1994) to its utmost limits and propose that the subjunctive itself, at least in Greek and in Rumanian, is a polarity item.

Grammars of Greek distinguish two moods, the indicative and the subjunctive, but it is not quite clear what exactly constitutes the subjunctive and the indicative morpheme. It has been argued that the Greek verb, contrary to the verb in Romance, is not inflected for mood. This is not entirely correct, however. It is true that there is no special affixal marking exclusively allotted to the subjunctive or to the indicative. Yet, there is a verbal form, the present perfective, which must be preceded by particles such as na, ja na, as and the conditional an 'if' in order to be grammatical, otherwise it is ruled out':

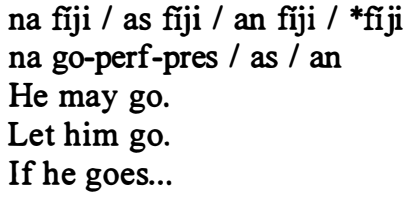

I take it that the subjunctive in Greek is expressed either by the particles na, ja $n a, a s, a n$ or the complex [particle + present perfective]. The rest of the verbal forms in the absence of any particle will be regarded as the indicative. To keep things simple, I concentrate on na-clauses.

A well-known property of the subjunctive in Greek as well as in other European languages is that it is selected in embedded clauses by certain classes of predicates which are traditionally described as irrealis. Yet, the selection pattern is subject to some puzzling variation across languages which exceeds the border of irrealis. For instance, factive verbs in the Romance subcategorize, quite surprisingly, for subjunctive complements. This and similar facts make a unified semantic characterization of either the subjunctive itself or the class of selecting predicates hard to justify.

Greek and Rumanian are very straightforward cases in that subjunctive selecting predicates can be properly characterized as non-veridical. Let me illustrate this for Greek (in Rumanian, the situation is parallel). Subjunctive is selected by the predicates grouped under (24): 
(24)

a desideratives (thélo 'want', elpizo 'hope', skopévo ' plan'

b directives (dhiatázo 'order', simvulévo 'advise', protíno 'suggest', parakaló 'to ask')

c modals (prépi 'must, deontic and epistemic', ine pithanón 'it is possible', ine anagéo 'it is necessary')

d predicates of fear (verba timendi) (fováme 'be scared')

Subjunctive clausal complements are further'selected by (e) prepositions like prin 'before', xoris/dhixos 'without' and andi 'instead', (f) the conditional particle an 'if', (g) negation and (i) the question operator. The following examples exemplify subjunctive selection by negation (ex.25)) and by the question operator (ex.(26)):

(25) a nomízo *na érthi / óti tha érthi o jánis think-1sg SUB-come / that FUT come-3sg the john I think that John will come.

b dhen nomízo na érthi o jánis not think-1sg SUB-come the John

I don't think that John will come.

(26) a kséro *na éfije i maría / óti éfije i maría know-1sg SUB-left the maria / that left the mary I know that Mary left.

b kséris na / óti éfije i maría?

know-2sg SUB leave-past the mary

Do you know whether Mary has left?

Do you know that Mary left?

Epistemic predicates in Greek and in Romance typically subcategorize for indicative complements, as shown in the $a$ sentences of (25)-(26). It is well documented in the literature (Farkas 1985, 1992, Manzini 1994, among others) however, that negation and the question operator can license the subjunctive in the complements of epistemic predicates. The indicative is also allowed in these cases as indicated by $(26, \mathrm{~b})$ but, crucially, subjunctive and indicative complements in these contexts are not synonymous. The subjunctive complement is interpreted inside the scope of the question and the epistemic operator whereas the indicative complement scopes over any other operator in the sentence. The two versions of (26b) can be paraphrased as follows:

(27) a Do you know if it is true that Mary left? (subjunctive)

b Mary left. Do you know this? (indicative)

I will not pursue this issue any further because doing so will lead us too far afield. What we should keep in mind is that all the subjunctive-selecting expressions are shown to obey non-veridicality: 
(28)

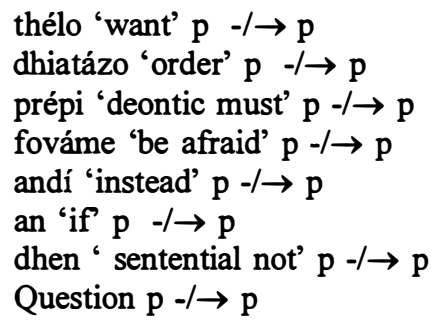

(28) establishes a parallel between the subjunctive and polarity items. We see that the subjunctive is sensitive to non-veridicality in the same way NPIs are. If we take the licensing condition put forth in Giannakidou (1994) as valid, we have to conclude that the selection of subjunctive in Greek and in Rumanian is nothing but an instance of NPI-licensing and that, in these languages, the subjunctive is triggered by a suitable non-veridical trigger in much the same fashion NPIs are triggered. The ungrammaticality of the subjunctive under epistemic, fiction, assertive and factive predicates is then reduced to a simple case of anti-licensing. Consequently, indicative turns out to be a positive polarity item (PPI) like the determiner some.

Crucially for our purposes, the subjunctive in the rest of Romance does not align with the Greek and the Romanian pattern. In French, Spanish, Catalan and Portuguese, the subjunctive is selected by non-veridical as well as by veridical operators such as the class of factive predicates. Given this and considering additionally that in the aforementioned languages NPIs cannot appear in subjunctive clauses, an interesting correlation emerges. It seems that languages can be divided into two groups with respect to which property they acknowledge as essential for NPI-licensing. The first group, consisting of Greek and Rumanian, opts for non-veridicality as the essential property. The second group, consisting of the rest of the Romance and the Germanic languages, opts for downward entailment. It ought to be emphasized that essential is not meant as exclusive but as mostly preferred. We have seen that even in the languages of the second type there are NPI-licensers which are not MD (c.f. questions). Now, in languages that opt for non-veridicality, we observe that only weak NPIs (in the spirit of Zwarts 1993, Giannakidou 1995 to appear) can be licensed by triggers which are non-veridical but not $\mathrm{MD} .^{5}$ Minimizers and polarity idioms are excluded from the scope of non-veridical/not MD operators, as the following contrast indicates:

(29) a thélo na pjó * ghouliá / kamja birítsa want-1sg SUB drink-1sg sip / any beer I want to drink a beer.

b dhen ípje ghouliá / kamja birítsa He didn't drink a drop.

Minimizers like pino ghuliá require non-veridical/MD licensers and the sentential complement of a desiderative does not qualify (see Giannakidou 1995 
to appear for details). In view of this, we may hypothesize that when a language displays sensitivity to non-veridicality even weaker polarity items can be licensed. The fact that the subjunctive is a polarity item in languages of that type comes as a natural consequence of the general "laxity" vis-a-vis NPIlicensing which is characteristic of these languages.

A final remark. The semantic claim that the subjunctive is a polarity item can easily be related to two recent approaches to the syntax of the subjunctive, namely the ones developed in Manzini (1994) and Tsoulas (1994). In Manzini (1994), the subjunctive is treated as an indefinite tense ( $T$ ) bound by an intensional operator in a syntactic dependency. In Tsoulas (1994), a parallel between subjunctive and indefinite NPs is established, based on their similar behaviour with respect to extraction phenomena, by means of which it is shown that the subjunctive behaves as an indefinite. I believe that associating the subjunctive with indefinites is on the right track, although it might not be the whole story. If we regard the subjunctive as some kind of indefinite we can understand why its selection is subject to variation across languages. In Greek and Rumanian, the subjunctive is a special case of indefinite, an NPI ${ }^{6}$, that is, an indefinite which can never be specific (referential) in the sense that it can never take wide scope with respect to the operator that licenses it. As an NPI, it is licensed by non-veridical operators and anti-licensed by the veridical ones (for instance, factive predicates do not select the subjunctive in Greek and Rumanian). In the rest of the Romance languages, the subjunctive is an indefinite which can, like all indefinites be specific (i.e. referential). This explains why the Romance subjunctive is selected by factive predicates ${ }^{7}$. The picture I've sketched here is quite tentative and there is certainly a lot more to be said on this matter. For reasons of space, I will stop here. It is the discussion of the habitual that I turn to next.

\section{Habituality and the licensing of NPIs}

In this section, I concentrate on the licensing of the Greek and Rumanian NPIs in sentences with imperfective aspect. It will be shown that (a) habituality is the aspect of imperfectivity relevant to their licensing and that (b) habitual sentences can be successfully analyzed as non-veridical. On these grounds, the proposal that non-veridicality triggers NPIs will gain further support.

\section{1 Imperfectivity, habituality, progressivity}

The kanénas indefinites are acceptable in sentences with imperfective aspect but not in sentences with perfective aspect:

(30) ótan thimótane, o jánis égrafe kanéna gráma ston patéra tou when remember-past-IMPRF-3sg,the john write-past-IMPERF3 sg any letter to-the father his Whenever he remembered, John wrote a letter to his father. 
* ótan thimíthike, o jánis égrapse kanéna gráma ston patéra tou when remember-past-PERF-3sg, the john write-past-PERF any letter to-the father his

When he remembered, John wrote a letter to his father.

The sentence in (30) is about a series of past events of John writing a letter to his father. Imperfective aspect serves as the appropriate marker to indicate that (30) is about a set of situations ${ }^{8}$ and not about one particular situation. By contrast, the ungrammatical sentence in (31) is intended as a communication of a single event in the past, an event which concerns John and which consists of his writing to his father at some point in time. The imperfective/perfective opposition in Greek reflects the habitual /episodic distinction. In view of the fact that habituality per se does not have any inherent monotonic properties, the grammaticality of kanéna gráma in (30) suggests that there is something to the semantics of the habitual other than monotonicity which is to be held accountable for the presence of polarity indefinites. Crucially, (31) is bad because it is embedded in the domain of episodic past. Episodic past is veridical, as designated in (31'). The ungrammaticality of the polarity indefinite is indeed predicted by the licensing condition in (21):

\section{(31') EPISODIC PAST [John write a letter] $\rightarrow$ John wrote a letter}

It is standardly assumed that the area of imperfectivity comprises two quite distinct concepts: habituality and progressivity (or continuousness or durativity, it depends on the terminology one chooses). In discussing the interaction between imperfectivity and NPIs one has to be clear as to what exacly should be associated with the grammaticality of sentences containing NPIs. (32) illustrates that the past progressive is not permeable to NPIs:

* ti stigmí pu o jánis milúse me kanénan filo tu sto tiléfono, égine to atíxima

the moment that the John talk-past-IMPERF with any friend his on the phone, happened-PERF the accident

While John was talking on the phone with a friend of his the accident took place.

It is beyond our interests here to discuss the theoretical problems raised by progressivity. Our immediate concern is to grasp that (32) is bad for exactly the same reason that (31) is bad, namely, because it is veridical. The veridicality of the past progressive is roughly expressed in (32'):

(32') EPISODIC PAST PROGR [John talks to $\mathrm{x}$ over the phone $\wedge$ accident takes place]

(32') tells us that the veridicality of the progressive is not inherent, but it follows from the fact that simultaneity is embedded under a veridical operator, 
which in this case is the episodic past. Naturally, if the progressive is embedded under a non-veridical operator we expect it to behave accordingly. (33) illustrates that if we embed (32) under éfxome 'wish', the NPI is licensed by non-veridicality:

(33) éfxome ti stigmí pu o jánis milái me kanénan filo tu sto tiléfono, na jíni to atíxima

I wish the accident happens while John is talking on the phone with a friend of his.

Embeddings under conditionals, questions etc. have exactly the same result. Since it is clear that the licensing condition in (21) accommodates these facts nicely, I will not wrestle with progressivity any further.

\section{2 The habitual as non-veridical}

\section{2. 1 Habituality and frequency}

(34) is a typical habitual sentence:

\section{John used to go to school on foot.}

Habitual sentences link a subject of 'specific' nature (a proper name, a definite or indefinite referential NP) to a predicate of 'generic' nature. Imperfective aspect in Greek flags the 'genericity' of the predicate. Habitual sentences are not about isolated events. Rather, they are about pluralities of events, they express habits or tendencies of individuals to act in a certain way. The feature common to all habituals is that they describe a situation which is characteristic of an extended period of time. Yet, habitual sentences do not only involve quantity. They possess a modal, law-like flavor which yields some vagueness in their truth conditions. It will turn out that this vagueness can be properly understood as an effect of non-veridicality.

Habituality is often, and correctly, associated with frequency and disassociated from iterativity. Vehicles of frequency and iteration are typically adverbs expressing the one or the other. Roughly speaking, iterative adverbs such as tris forés 'three times' and merikés forés 'several times' count events. They specify the cardinality of a set of situations and this cardinality is conceived of as an absolute quantity. Frequency adverbs (Q-adverbs) such as sixná 'often' and spánia 'rarely' do not count events, they do not involve absolute quantity. When speakers of natural languages employ Q-adverbs they mean to show that they are not interested in the cardinality (absolute or not) of a set of events. Instead, the use of Q-adverbs suggests that the speaker considers the set of events vis-a-vis a given interval and according to the lexical meaning of the adverb (s)he judges the frequency as high or low or some other value along the scale. 
The split between frequency and iterativity is well-motivated given the fact that iterative and frequency adverbs do not exemplify the same combinatorial possibilities with tense and aspect. As a rule, in languages like Greek and French, iterative adverbs combine with perfective, contrary to Qadverbs which combine with the imperfective. Q-adverbs are often present in habitual sentences and their presence is sometimes crucial for the licensing of the polarity indefinites as the oddness of (35) indicates:

\section{??pernúse kanénas fititís} pass-by-past-IMPERF any student

??A student used to pass by (no particular student)

As we have already seen, the imperfective morpheme is ambiguous in Greek between the progressive and the habitual and this ambiguity is responsible for the oddity of (35). The presence of an adverbial or of a temporal clause lends prominence to the relevant interpretation. So, if (34) is enriched with a clause like when my car broke down, it is understood as expressing a simultaneity of events, thus the imperfective would be interpreted as progressive and (35) would remain bad. On the other hand, adding something like on Mondays or usually, brings the habitual interpretation about and (35) undergoes dramatic improvement.

I assume a theory about adverbial quantification along the lines of De Swart (1992), according to which Q-adverbs are envisioned as generalized quantifiers (GQs) over eventualities. The monotonicity properties of quantifiers denoted by the Q-adverbs seem to play no role for NPI-licensing. The following sentences illustrate this point:

pu ke pu, pernúse kanénas fititís

the momings, pass-by-past-IMPERF any student

Students would pass by every now and then.

o Jánis mas éferne sixná sto spíti kanénan filo tu ja fajitó

the john us bring-past-IMPERF often any friend his for food

John would often brings home a friend of his for dinner.

tis kirjakés, évgaza siníthos ton skílo ja kamjá vólta sto párko

in-the Sundays, take-past-IMP-1sg usually the dog for any walk

in-the park

On Sundays, I would usually take the dog in the park for a walk.

In (36), $p u$ ke $p u$ denotes a MD quantifier so the licensing of kanénas fititis comes as no surprise if one assumes a monotonicity based theory. In (37), sixná denotes a monotone increasing (MI) quantifier and in (38), sinithos can be taken to denote an inherently vague quantifier which can be paraphrased by 'a significant number of'. If we take the cardinality of 'a significant number of' to be translatable into the cardinality of most, then see that usually denotes a MI quantifier too and the grammaticality of the NPIs in (37)-(38) is then quite unexpected. The fact that NPIs are licensed in habitual sentences regardless of 
the monotonic properties of the Q-adverbs occurring shows that monotonicity is not relevant for the licensing in habituals. Crucially, NPIs are not licensed when the Q-adverb denotes a universal quantifier. This suggests that the universal/non-universal parameter is indeed relevant:

* káthe kirjakí, o jánis éferne sto spíti kanénan filo tu ja fajitó. every Sunday the John brought-IMPERF in-the house any friend his for food

Every Sunday, John would bring home a friend of his for dinner.

káthe kirjaki 'every Sunday' induces the universal force of the habitual in (39) with a bad result. This ungrammaticality should be linked to the unacceptability of NPIs in generic sentences, as shown in (40):

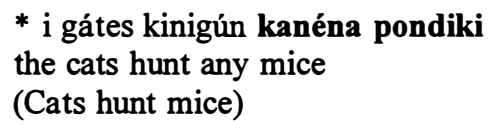

In view of this, the apparent conclusion has to be that reference to a plurality of events is not the only facet of habituality that makes it qualify for an NPItrigger. Rather, the nature of this plurality seems to play the decisive role. Habituality associated to universal quantification is not an environment accessible to NPIs. Habituality pertinent to non-universal quantification is. In the next section I will try to show why this is so.

\section{How to interpret habitual interpretation}

I assume that habituality is expressed by a habitual operator $\mathrm{HAB}$ which functions at the sentential level. I regard Q-adverbs, when present, as the morphological realizations of the habitual operator which in principle need not be realized overtly. ${ }^{10}$ In cases where a Q-adverb is not present I conjecture the covert presence of an adverb such as sinithos 'usually'. I am also assuming, following standard practice, that the habitual operator, like any other adverbial quantifier, performs restricted quantification in much the same fashion that nominal quantifiers do. Hence, for the interpretation of habitual quantification, I am assuming a tripartite structure consisting of the operator and its two arguments as in (41):

\section{Op [Restrictor] [Matrix]}

The first argument (the restrictor) provides the relevant set of cases /situations the quantifier ranges over. The second argument (the matrix) supplies the main predication. Now consider (42):

(42) John usually riffles through a magazine when he goes to bed. 
The semantic structure of (42) is articulated in $\left(42^{\prime}\right)^{11}$ :

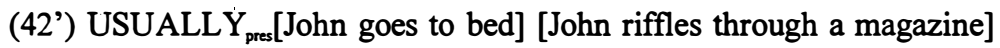

For simplicity and since it plays no important role in the analysis pursued here, I ignore the fact that usually can eventually take narrow scope with respect to the when-clause. I also ignore temporal issues. In (42'), $\mathrm{HAB}$ quantifies over the set of situations in which John goes to bed and relates them to the set of situations in which John riffles through a magazine. Due to the lexical meaning of USUALLY (most), the relation between the two sets is such that the number of situations in which John goes to bed and riffles through a magazine is bigger than the number of situations in which John goes to bed and does not riffle through a magazine. This relation is represented in (43) (where A stands for the set denoted by the restrictor and B stands for the set denoted by the matrix):

$$
\operatorname{USUALLY}(\mathrm{A}, \mathrm{B})=1: \quad|\mathrm{A} \cap \mathrm{B}|>\mid \mathrm{A}-\mathrm{B}_{\mid}^{\prime}
$$

If (42) contained rarely the following structure would be yielded:

$$
\text { RARELY }_{\mathrm{pr}} \text { [John goes to bed] [John riffles through a magazine] }
$$

Here, the set of situations in which John goes to bed is related to the set of situations in which John riffles through a magazine but the lexical meaning of rarely tells us that the number of situations such that John goes to bed and riffles through a magazine is smaller than the number of situations such that John goes to bed and does not riffle through a magazine. This is expressed in (44):

$$
\operatorname{RARELY}(A, B)=1: \quad\left|A \cap B_{1}^{\prime}<\right| A-B_{1}^{\prime}
$$

In modal-semantic terms, the logical form of habitual structures can be interpreted as follows. The habitual operator is conceived of as an intensional operator in the sense of Farkas (1992) and MacCawley (1980). Hence, it is taken to introduce a set of possible worlds into the domain of quantification, be it $\mathrm{W}_{\text {нав}}$, just like modals and subjunctive selecting predicates do. $\mathrm{W}_{\text {нав }}$ consists of worlds which stand for possible future, past or present situations. I assume, with Farkas 1992, that $\mathrm{W}_{\text {нив }}$ is always anchored to an individual $\mathrm{x}$, namely to the referent of the main clause subject. So we have $\mathrm{W}_{\text {нАВ }}(\mathrm{x})$. In case the individual anchor is the speaker, $\mathrm{W}_{\text {нив }}$ denotes possible present situations relative to him/her, thus $\mathrm{W}_{\text {нАВ }}(\mathrm{s})$. The nature and the structuring of $\mathrm{W}_{\mathrm{HAB}}(\mathrm{x})$ is essentially determined by the lexical meaning of $\mathrm{HAB}$. If HAB does not induce universal quantification, $\mathrm{W}_{\mathrm{HAB}}(\mathrm{x})$ is partitioned into a subset, call it $\mathrm{W}^{\prime}$ and its complement. The worlds in W' satisfy the truth conditions of the complement of $H A B$, that is $W^{\prime} \subseteq W p$, where $p$ is the complement of $H A B$ and $W p$ is the set of worlds in which $\mathrm{p}$ is true. The worlds in - $\mathrm{W}^{\prime}$, the complement set of $\mathrm{W}^{\prime}$, do not satisfy the truth conditions of $p$, that is $-W^{\prime} \cap W p=\varnothing$. I argue that the 
non-veridical character of (non universal) $\mathrm{HAB}$ resides precisely in the fact that $\mathrm{W}_{\mathrm{HAB}}(\mathrm{x})$ is partitioned, so that (45) holds:

$$
\mathrm{HAB} p-/ \rightarrow p
$$

We can now disentangle the mystery of universal and generic sentences. Consider the sentences in (46) and their logical forms in (47):

(46) a John always riffles through a magazine when he goes to bed b Cows eat grass

(47) ALWAYS [John goes to bed] [John riffles through a magazine] GEN [cows] [cows eat grass]

The correct treatment of generics is of course a complicated matter and it can not be tackled in this paper. Intensionality issues aside, the truth conditions of universal and generic quantifiers are given in (48):

$$
\begin{array}{lll}
\text { a } & \text { ALWAYS }(A, B)=1: & A \cap B=A \text { or } A \subseteq B \\
\text { b } & \text { GEN }(A, B)=1: & A \cap B=A \text { or } A \subseteq B
\end{array}
$$

According to (48a), (46a) communicates that all instances of John's going to bed are instances of John's going to bed and riffling through a magazine. Crucially, for (46a) to be true there must be no instance of John's going to bed and not riffle through a magazine. For (46b) I assume a similar strategy. All instances of cows are instances of grass eating cows ${ }^{12}$. To phrase it otherwise, (46a,b) express that A - B is empty in all possible situations. In modal semantic terms we have to say that, if $\mathrm{HAB}$ is universal/generic, all worlds in $\mathrm{W}_{\mathrm{HAB}}(\mathrm{x})$ satisfy the truth conditions of $\mathrm{p}$, that is $\mathrm{W}_{\mathrm{HAB}}(\mathrm{x}) \subseteq \mathrm{Wp}$. $\mathrm{W}_{\mathrm{HAB}}(\mathrm{x})$ is not partitioned, hence universal/generic HAB is veridical:

$$
\text { ALWAYS/GEN } \mathrm{p} \rightarrow \mathrm{p}
$$

The ungrammaticality of NPIs in universal habituals and generic sentences, as exemplified in (39) and (40), is no longer puzzling. NPIs are triggered only in non-veridical contexts. Universal habituals and generic sentences are veridical, therefore the occurrence of NPIs is not felicitous.

Tradition has it that habituality and genericity are essentially one and the same thing. After all, habituality is temporal genericity. The NPI-licensing facts in Greek challenge this conviction and reveal an interesting difference between the two pertaining to their quantificational properties. To this end, I suggest that the traditional view should, if not be revised, at least be reconsidered. 


\section{Conclusion}

In this paper I have proposed a theory for NPI-licensing which attributes the licensing potential to non-veridicality. Evidence in favor of this theory was provided by the grammaticality of NPIs in subjunctive and habitual sentences, as exemplified in Greek and Rumanian. It has been shown that subjunctive and habitual (non-universal) contexts can be successfully analyzed as non-veridical and that the notion of habituality should be kept distinct from the notion of genericity vis-a-vis NPI-licensing. Furthermore, I have pointed out that an interesting consequence of this proposal is to regard the subjunctive itself as a polarity item. The explanatory power of the non-veridicality hypothesis proves very satisfactory, yet more research is certainly needed. A lot of questions still remain open, for instance, questions concerning the syntactic conditions on licensing or the diversity attested in NPI-distribution. Giannakidou (1995, to appear) suggests that it is possible, within the framework developed here, to account for these problems in a precise and straightforward way.

\section{Endnotes}

* While engaged in this research, I enjoyed the help, sometimes inestimable, of many people. I want to express my gratitude to E. Anagnostopoulou, D. Farkas, D. Gierling, J. Hoeksema, H. Klein, Ch. Koster, J. Quer, V. Sanchez-Valencia, H. de Swart, G. Tsoulas and F. Zwarts. A special word of public thanks to J. Sola for sharing my fascination with the subjunctive and for endlessly discussing these issues with me.

1. For a more extensive critique on monotonicity-based theories for NPIs the reader should consult Krifka (1994) and Giannakidou (1994).

2. This licensing condition should not be taken to mean that every non-veridical operator must license NPIs. Rather, it should be regarded as a claim that whenever NPIs are licensed, it is non-veridicality that licenses them and not something else.

3. Veridicality judgements are sensitive to temporal considerations as well as to the retrospective/prospective parameter. before, for instance, is veridical under the restrospective viewpoint and non-veridical under the prospective. Temporal interpretation should be fixed before the characterizations veridical/nonveridical apply.

4. Interestingly, free relatives constitute another grammatical context for the present perfective. The conditional particle is admitted in free relatives too. This fact further supports a connection between the subjunctive and the conditionals.

5. Consider that, with the exception of English, the languages that show sensitivity mostly to downward entailment lack polarity indefinites like the English any, the Greek kanénas and the Rumanian vreo. We can assume that since polarity indefinites are the only weak NPIs known and since in the languages under discussion weak NPIs are not available, it is natural to expect 
orientation to downwrd entailment and not to non-veridicality. I admit that this situation might look a bit like the egg-chicken problem, but I believe that the basic intuition is clear.

6. As far as I know, Ladusaw was the first to propose that NPIs should be treated as indefinites in the classic Heimian sense. See Ladusaw 1992, 1994 for details.

7. Thanks to Jaume Sola for discussing these issues with me and offering valuable suggestions.

8. I use the terms event and situation quite atheoretically here. I mean to use them as purely descriptive labels without making any commitment to specific theoretical frameworks.

9. See for details the discussion on generally in Farkas and Sugioka (1983).

10. There are two arguments in favor of the sentential character of the habitual operator. First, it may take wide scope over the clausal subject as exemplified by topicalized constructions. Second, the habitual operator creates opaque contexts. This is in accordance with the diagnostics developed in the philosophical tradition (inter alia, Thomason and Stalnaker (1973), Parsons (1990)) according to which a modifier is a sentence operator only if it gives rise to opacity.

11. The structure of (39) can also be captured by a scheme like the following:

(a) USUALLY [John goes to bed] [John goes to bed and riffles through a magazine]

which reflects the idea that usually the events of John's going to bed are events of John's going to bed and riffling through a magazine. This representation would be preferable in a framework like Groenendijk \& Stokhof $(1990,91)$.

12. Exceptions are naturally tolerated but the way tolerance to exceptions is accomodated within an analysis which treats generic statements as universal statements falls beyond our immediate concerns.

\section{References}

Farkas, D.F. (1985). Intensional Descriptions and the Romance Subjunctive mood, Garland, New York

Farkas, D.F. (1992). On the semantics of subjunctive complements. In Hirschbuehler P. et al. (eds), Romance Languages and Modern Linguistic Theory, John Benjamins

Fauconnier, G. (1975). Polarity and the scale principle. In CLS 11,18899, Chicago Linguistic Society

Giannakidou, A. (1993). KANIS / kanis, a case of polarity sensitivity in Modern Greek. In Studies in Greek Linguistics 14:130-144, University of Thessaloniki

Giannakidou, A. (1994). The semantic licensing of NPIs and the Modern Greek subjunctive. In De Hoop H. et al. (eds) Language and Cognition 4:55-68, Yearbook of the Research Group for Theoretical and Experimental Linguistics, University of Groningen

Giannakidou, A. (1995,to appear). Weak and strong polarity. In the Proceedings of The Workshop on Greek Syntcox, FAS, Berlin 
Heim, I. (1982). The Semantics of Definite and Indefinite NPs. $\mathrm{PhD}$ Dissertation, Un. of Massachusetts, Amherst

Horn, L. (1972). On the Semantic Properties of Logical Operators in English. PhD Dissertation, UCLA

Kleiber, G. (1987). Du cote de la référence verbale: les phrases habituelles, . Peter Lange, Paris

Krifka, M. (1994). The semantics and pragmatics of weak and strong polarity items in assertion. In the Proceedings of SALT IV:195-219, Cornell University

Ladusaw W.A., (1980). Polarity Sensitivity as Inherent Scope Relations, $\mathrm{PhD}$ Dissertation, University of Texas, Austin

Ladusaw, W.A. (1992). Expressing Negation. In SALT II Proceedings: 237-59, Cornell University

Ladusaw, W.A. (1994). Thetic \& Categorical, Stage \& Individual, Weak \& Strong. In the Proceedings of SALT IV:220-29, Cornell University

Manzini R. (1994). The Subjunctive. In Lea Nash et.al. (eds), Paris-8 Working Papers in Linguistics

McCawley, J.D. (1980). Everything that linguists have always wanted to know about Logic (and were afraid to ask). Basil Blackwell, Oxford

Philippaki-Warburton, I. and Veloudis, I.(1984). The subjunctive in complement clauses. In Studies in Greek Linguistics 5, University of Thessaloniki, Greece, 73-89

Sanchez-Valencia, V. et al.(1993). Polarity and the flow of time. In Language and Cognition 3

Swart, H. de. (1992). Adverbs of Quantification: a Generalized Quantifier approach, $\mathrm{PhD}$ Dissertation, University of Groningen

Thomason, R. \& Stalnaker R. (1973). A semantic theory of adverbs, Linguistic Inquiry 9, 195-220

Tsoulas G. (1994). Subjunctives as Indefinites. In the Proceedings of the XX Incontro de Grammatica Generativa, Padova

Zwarts F. (1986). Categoriale Grammatica en Algebraische Semantiek, $\mathrm{PhD}$ dissertation, University of Groningen

Zwarts, F. (1993). Three types of polarity. To appear in Hamn F. and Hinrichs E.(eds) Semantics 